\title{
Poor prognosis of patients presenting with symptomatic myocardial infarction but without chest pain
}

M F Dorsch, R A Lawrance, R J Sapsford, N Durham, J Oldham, D C Greenwood,
B M Jackson, C Morrell, M B Robinson, A S Hall, for the EMMACE Study Group*

\begin{abstract}
Objective-To describe the clinical features, prognosis, and treatment of patients presenting with atypical forms of acute myocardial infarction.

Design-Consecutive cases of possible acute myocardial infarction were sought from coronary care registers, biochemistry records, and hospital management systems. Case notes were reviewed and predefined epidemiological and clinical variables were abstracted.

Setting-20 adjacent hospitals in the former Yorkshire region.

Patients-3684 consecutive cases of possible acute myocardial infarction admitted in a three month period were identified, of whom 2096 had a first episode of confirmed acute myocardial infarction.

Results-20.2\% of all patients admitted with an eventual diagnosis of acute myocardial infarction presented with symptoms other than chest pain. Compared with the group presenting with chest pain, these patients were older $(76.6 v 69.1$ years, $\mathrm{p}<0.001)$, were more often women $(54.6 \% v 35.3 \%, \mathrm{p}<0.001)$, and were more likely to have a history of heart failure $(18.6 \% v$ $6.9 \%, \mathrm{p}<0.001)$. They had a higher 30 and 365 day mortality $(49.2 \%$ and $61.0 \%$, respectively) compared with patients presenting with chest pain $(17.9 \%$ and $26.2 \%)$. In a Cox regression analysis the hazard ratio for presentation without chest pain was 1.60 (95\% confidence interval 1.30 to 1.97 ) ( $\mathrm{p}<0.001$ ) adjusted for age, heart rate, blood pressure, left ventricular impairment, and infarction with ST segment elevation as covariates. Importantly, they were also less likely to receive treatments with a proven ability to improve prognosis.

Conclusions-Atypical presentation of myocardial infarction without chest pain is common and associated with increased mortality. This may result in part from a failure to use beneficial treatment strategies.
\end{abstract}

(Heart 2001;86:494-498)

Keywords: acute myocardial infarction; atypical presentation

Patients with acute myocardial infarction usually present with chest pain. However, atypical presentations of this common condition are well recognised. Data from the Framingham study suggest that $25 \%$ of acute myocardial infarcts occurring among the participants during 30 years of follow up were only apparent after an examination of the ECG. In almost half of these cases the myocardial infarction was truly "silent" and the remainder were accompanied by atypical symptoms. ${ }^{1}$

Only a few investigations have looked into the subgroup of symptomatic patients with acute myocardial infarction presenting to hospital without chest pain. Potential weaknesses of these studies include the small number of patients recruited, selection bias because of the use of clinical trial populations, and the selective study of certain subpopulations such as specific age groups or those where the diagnosis of acute myocardial infarction was suspected during initial assessment in the emergency room..$^{2-7}$

We therefore decided to evaluate a large number of patients of all ages, who presented with symptomatic myocardial infarction without chest pain and who were consecutively admitted into one of 20 adjacent hospitals. We wished to describe the characteristics and survival outcome of these as compared with patients with the more typical presenting feature of chest pain.

\section{Methods}

PATIENT POPULATION

Over a three month period (1 September to 30 November 1995), 3684 potential cases of acute myocardial infarction in 20 adjacent hospitals in the Yorkshire region were identified from coronary care registers, clinical coding, and biochemistry records of cardiac enzyme assay requests. The different search strategies were complementary - that is, a significant number of cases that were later validated would have been missed if only one of the search strategies, such as coronary care registers, had been employed. Consecutive patients of all ages with confirmed acute myocardial infarction (final diagnosis reached by the most senior member of the attending physician team) were included in the study.

A 250 item case record form listing demographic, clinical, and treatment variables was completed for each patient with confirmed acute myocardial infarction, according to a standardised operations manual, and entered onto a computer database; all consecutive 
Table 1 Baseline characteristics of the patients

\begin{tabular}{llll}
\hline & $\begin{array}{l}\text { With chest pain } \\
(n=1661)\end{array}$ & $\begin{array}{l}\text { Without chest pain } \\
(n=421)\end{array}$ & p Value \\
\hline Age (years) & $69.1(11.8)$ & $76.6(10.7)$ & $<0.001$ \\
Female (\%) & 35.3 & 54.6 & $<0.001$ \\
$\begin{array}{l}\text { Previous history } \\
\text { Recorded (\%) }\end{array}$ & & \\
$\begin{array}{l}\text { Diabetes (\%) } \\
\text { CCF (\%) }\end{array}$ & 99.6 & 99.0 & 0.174 \\
Admission characteristics & 12.2 & 15.3 & 0.090 \\
Heart rate & 6.9 & 18.6 & $<0.001$ \\
Blood pressure & $81(23)$ & & $<0.001$ \\
& $141 / 83(31 / 19)$ & $130 / 75(37 / 24)$ & $<0.001$ \\
$\begin{array}{l}\text { Investigational characteristics } \\
\text { ST elevation on first ECG }\end{array}$ & $788 / 1573(50 \%)$ & $127 / 372(34 \%)$ & $<0.001$ \\
Mean peak CK & $1373(1403)$ & $1335(1678)$ & 0.693 \\
LV impairment & $572 / 1255(46 \%)$ & $170 / 312(55 \%)$ & 0.005 \\
\hline
\end{tabular}

Values are $\mathrm{n}$ or mean (SD).

${ }^{\star}$ Objective evidence for left ventricular impairment (chest $x$ ray, echocardiogram, nuclear scan, left ventricular angiogram)

$\mathrm{CCF}$, congestive cardiac failure; CK, creatinine kinase; LV, left ventricular.

patients with acute myocardial infarction were included regardless of age or place of care within the hospital. Only one event was included (the first presentation with an acute myocardial infarct during the recruitment window), and patients transferred to a tertiary centre were counted only once for the index admission. Patients were excluded from the study if they died in the ambulance or in the accident and emergency department.

Two senior research nurses and an experienced cardiology registrar abstracted the presenting symptoms from the case notes. To decide whether chest pain was among the presenting features, all available information was screened, including ambulance, emergency room, nursing, and all available medical notes (not just the initial clerking). If no reference was made to chest pain in all of this, it was assumed that the patient did not have chest pain.

The quality of data abstraction from case notes and data entry into the computerised

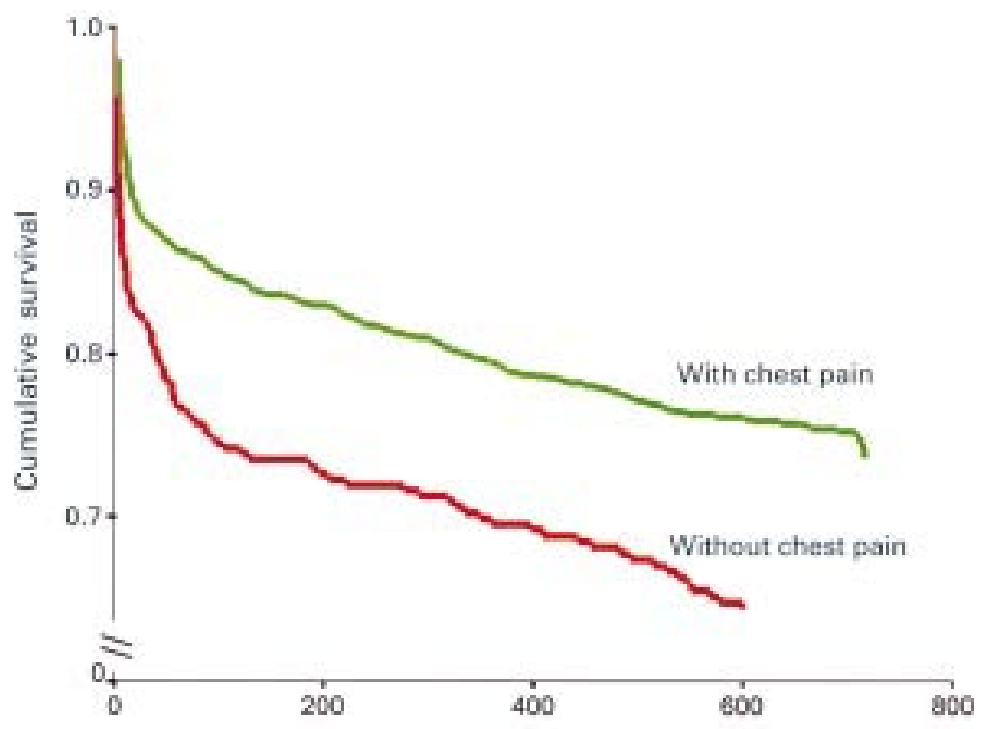

Survival from admission (days)

Figure 1 Cox regression survival curves with age, heart rate, systolic blood pressure, and objective evidence of left ventricular impairment on admission as covariates $(n=2096)$ for patients presenting with and without chest pain.
Table 2 Main symptom at the time of presentation

\begin{tabular}{ll}
\hline Presenting complaint & $\begin{array}{c}\text { Per cent of total } \\
(n=421)\end{array}$ \\
\hline Shortness of breath & 31.8 \\
Collapse & 16.2 \\
Upper body discomfort other than chest pain & 13.1 \\
Cardiac arrest & 10.5 \\
Neuropsychiatric presentation & 5.9 \\
Perioperative & 4.0 \\
Perspiration & 2.4 \\
Nausea/vomiting & 2.1 \\
Non-specifically unwell & 14.0 \\
\hline
\end{tabular}

database was formally assessed. During a pilot phase which was not included in the final dataset, the interobserver agreement rate for data abstraction from case notes was $98 \%$, without any systematic bias. The accuracy of data entry into the database was excellent, with a discrepancy rate of less than $1 \%$ and without systematic bias.

BENEFICIAL TREATMENT STRATEGIES

Prescription of aspirin and $\beta$ blockers on discharge was evaluated according to the American College of Cardiology/American Heart Association guidelines relevant in $1995 .^{8}$ Angiotensin converting enzyme (ACE) inhibitors were considered to be indicated in those patients who fulfilled the entry criteria of one of the large trials that had been published at the time of our study. ${ }^{9} 10$ The use of statins was assessed according to the criteria of the Scandinavian simvastatin survival study. ${ }^{11}$

\section{STATISTICAL ANALYSIS}

Baseline variables and process of care variables in groups with and without chest pain were compared using the $\chi^{2}$ test for categorical data. For continuous variables at baseline the two sample $t$ test was employed. Process of care variables were adjusted for age and sex by regression. The effect of age and sex on presentation with and without chest pain was analysed by multivariate logistic regression. Cox regression analysis was used to analyse survival for patients presenting with and without chest pain.

\section{Results}

On evaluation of the medical records, 2096 consecutive patients with acute myocardial infarction were confirmed. Of those, $421(20.2 \%)$ presented with symptoms other than chest pain. Information on whether chest pain was present was missing in 14 patients $(0.7 \%)$.

Demographic and clinical baseline characteristics for the subgroups with and without chest pain are given in table 1. Patients who presented without chest pain were older and were more likely to be female or to have had a history of congestive heart failure. More patients presenting with chest pain had ST segment elevation on their first ECG. There was no difference in maximum enzyme rise between the two subgroups. A higher proportion of patients presenting without chest pain had objective evidence of left ventricular impairment. There was also a trend for there to be more diabetic patients in this group. 
Table 3 Process of care variables for subgroups of patients with and without chest pain

\begin{tabular}{lllll}
\hline & With chest pain & Without chest pain & p Value & Odds ratio ${ }^{*}(95 \%$ CI $)$ \\
\hline Managed on coronary care unit & $1264 / 1642(77.0 \%)$ & $162 / 412(39.3 \%)$ & $<0.001$ & $0.27(0.21$ to 0.34$)$ \\
Cardiac rehabilitation programmet & $872 / 1107(78.8 \%)$ & $83 / 153(54.2 \%)$ & $<0.001$ & $0.48(0.33$ to 0.70$)$ \\
Followed up by cardiologist & $566 / 1311(43.2 \%)$ & $42 / 195(21.5 \%)$ & $<0.001$ & $0.52(0.36$ to 0.77$)$ \\
Coronary angiogram during admission & $80 / 1657(4.8 \%)$ & $5 / 420(1.2 \%)$ & 0.030 & $0.36(0.14$ to 0.90$)$ \\
Revascularisation during admission & $34 / 1675(2.1 \%)$ & $3 / 420(0.7 \%)$ & 0.201 & $0.46(0.13$ to 1.52$)$ \\
\hline
\end{tabular}

*Adjusted for age and sex.

†Denominator: those eligible according to local guidelines.

The effect of sex on presentation with or without chest pain remained significant after adjustment for age (odds ratio (OR) for a woman to present without chest pain, 1.5 (95\% confidence interval (CI) 1.27 to 2.01 ), $\mathrm{p}<0.001)$. Increasing age was strongly associated with no chest pain (OR per additional year of age, 1.06 (95\% CI 1.05 to 1.07$)$, p < 0.001).

Figure 1 shows Cox regression survival curves for the groups with and without chest pain (hazard ratio without chest pain, 1.60 (95\% CI 1.30 to 1.97 ), $\mathrm{p}<0.001$ ), with the following as covariates: age (hazard ratio per additional year of age, 1.06 (95\% CI 1.05 to $1.07), \mathrm{p}<0.001$ ), heart rate (hazard ratio per additional beat $/ \mathrm{min}, 1.01$ (95\% CI 1.01 to $1.01), \mathrm{p}<0.001)$, systolic blood pressure on admission (hazard ratio per additional $\mathrm{mm} \mathrm{Hg}$, 0.99 (95\% CI 0.99 to 0.99 ), $\mathrm{p}<0.001$ ), objective evidence for left ventricular impairment (hazard ratio, 2.07 (95\% CI 1.70 to 2.53), $\mathrm{p}<0.001$ ), and ST segment elevation on first ECG (hazard ratio for ST elevation, 0.76 (95\% CI 0.63 to 0.92$), p=0.005)$. Patients who present with symptoms other than chest pain had an early and late mortality that was significantly higher than that of their counterparts presenting with chest pain.

Table 2 shows the main presenting symptoms for the patients without chest pain. The most common presentation was shortness of breath, followed by collapse and upper body discomfort other than chest pain.

Tables 3 and 4 show treatment age and sex adjusted strategies used for the subgroups with and without chest pain. Patients presenting without chest pain were less likely to be managed on a coronary care unit, to be enrolled in a cardiac rehabilitation programme, or to be followed up by a cardiologist. In addition, they were also less likely to be discharged on aspirin and $\beta$ blockers for secondary prevention (corrected for age, sex, and contraindications to the use of these drugs).

\section{Discussion}

We have described a group of consecutive patients with acute myocardial infarction

Table 4 Drugs of benefit not prescribed at discharge despite absence of contraindication

\begin{tabular}{lllll}
\hline & With chest pain & Without chest pain & p Value & Odds ratio \\
\hline Aspirin & $58 / 1267(4.6 \%)$ & $29 / 184(15.8 \%)$ & $<0.001$ & $2.72(1.65$ to 4.51$)$ \\
$\beta$ Blocker & $129 / 751(17.2 \%)$ & $30 / 66(45.5 \%)$ & $<0.001$ & $2.66(1.51$ to 4.69$)$ \\
ACE inhibitor & $201 / 672(29.9 \%)$ & $46 / 128(35.9 \%)$ & 0.619 & $1.11(0.74$ to 1.67$)$ \\
Statin & $181 / 291(62.2 \%)$ & $13 / 21(61.9 \%)$ & 0.822 & $0.90(0.35$ to 2.30$)$ \\
\hline
\end{tabular}

*Adjusted for age and sex.

$\mathrm{ACE}$, angiotensin converting enzyme. presenting without chest pain who were admitted to adjacent hospitals, without focusing on specific admission areas or age groups.

Comparing our findings with previous data, Goldstein and colleagues found that $4.7 \%$ of patients in the multicentre diltiazem postinfarction trial presented without chest pain. ${ }^{3}$ The main cause for this discrepancy is most likely to be the well described selection bias of large randomised clinical trials. Herlitz and colleagues analysed 921 cases of acute myocardial infarction admitted to a single hospital and found that $7 \%$ presented without chest pain. ${ }^{5}$ The lower rate in that study than in our population can be explained by a different search strategy. Herlitz and colleagues included patients who presented to the emergency room with symptoms that raised the suspicion of acute myocardial infarction. In contrast, our search strategy will have allowed us to include those patients who were shown to have an acute myocardial infarct during their hospital stay, although this was not expected on admission. The numbers of such cases seem quite substantial. In our dataset, $17 \%$ of all patients who turned out to have an infarct had an admission diagnosis other than acute myocardial infarction, angina (stable and unstable), or chest pain of unknown cause. This should explain the discrepancy in relative frequencies between our study and that of Herlitz and colleagues. ${ }^{512}$ Our data are supported by those of Uretsky and associates, who retrospectively analysed a small series $(n=102)$ of patients with acute myocardial infarction admitted to a single hospital and found that $25.5 \%$ of patients presented without chest pain. ${ }^{2}$

The effects of age and sex on the occurrence of chest pain in acute myocardial infarction have been described previously. It is generally accepted that older patients with acute myocardial infarction are less likely to present with chest pain. ${ }^{235}$ However, in our study women with acute myocardial infarction, even after correction for age, were more likely to present without pain. This is in line with a small study published by Muller and colleagues, ${ }^{4}$ but is in contrast to most of the previously published data. $^{2357}$ The pathophysiological background for this phenomenon remains unexplained. Other differences between subgroups - such as the higher proportion of patients with a history of congestive heart failure or diabetes in the group without chest pain-have also been described previously. ${ }^{5}$

Most of the patients without chest pain in our study (32\%) sought medical help for 
breathlessness. Goldstein and colleagues quote a similar figure, although in their study group most patients presented with atypical upper body discomfort (39\%). ${ }^{3}$ The differences probably reflect differences in patient recruitment as described above.

The early and late mortality rate was nearly twice as high in the patients presenting without chest pain. Most of the differences are likely to be explained by the higher risk factor profile of the group presenting without chest pain. On average this group was older and more likely to have a history of congestive heart failure or evidence of left ventricular impairment. There was also a trend for the group to contain more diabetic patients. All these factors have been associated with a higher risk of death. However, we have previously shown on univariate logistic regression that presentation without chest pain is a strong predictor of 30 day mortality. ${ }^{13}$ Even in multivariate logistic regression, when tested together with all the variables given in table 1 it remains a predictive factor (data not shown). Again the mechanism underlying this remains unexplained. It is possible that it is an additive surrogate for more severe disease on admission - that is, for people too severely ill to complain of chest pain. This is certainly possible for those patients who present with collapse, cardiac arrest, or neuropsychiatric features. It is likely that retrograde amnesia and altered sensorium in this subgroup prevents them from complaining of chest pain. However, most of the patients (table 2) admitted to some symptoms on admission, so it seems likely that if they had had chest pain they would have mentioned that as well.

Another intriguing finding is that the group presenting without chest pain is less likely to receive management/treatment strategies of proven prognostic benefit. Failure to use early strategies such as admission to a coronary care unit can be explained by the fact that the diagnosis is not expected on admission. However, at discharge the diagnosis had been established but nevertheless preventive treatment strategies were still heavily underemployed in this high risk subgroup presenting without chest pain. Reasons for this may include preferential focus of doctors on symptomatic rather than prognostic treatment strategies. A second explanation might be that these treatment strategies are underused because the diagnosis was often made late and the patient was therefore not initially categorised as "cardiac", with the result that the beneficial treatment strategies were overlooked. It is noteworthy that, even when corrected for age and sex, patients who presented without chest pain were less likely to receive evidence based management/treatment strategies. It is interesting to speculate, therefore, how much of the poor outcome of this subgroup without chest pain is attributable to the poorer treatment received.

The infrequent use of invasive or interventional procedures during the index admission in our experimental groups is likely to be a UK phenomenon, where cost pressures on the health care system result in fewer such procedures than in the USA or continental Europe. ${ }^{14}$ The massive underuse of statins in both subgroups again reflects UK practice in 1995. At that stage explicit funding for large scale cholesterol lowering treatment was not available in most hospitals in the UK, although the benefit of statins was already proven. ${ }^{11}$

\section{LIMITATIONS}

There are some limitations to our study. It was done retrospectively and the available data depend mainly on the quality of the information recorded by the physicians looking after each patient. Data abstraction from the case notes and data entry into the computerised database were, however, done with good interobserver agreement and without systematic bias.

\section{CONCLUSIONS}

We have described the clinical characteristics of patients presenting with symptomatic myocardial infarction but without chest pain. We have shown that this subgroup of patients represents a high risk population that is less likely to receive treatment strategies of proven prognostic benefit. Recognition of the problem and of the increased risk is clearly the first step. It is our hope that current strategies such as early risk stratification by troponins or the implementation of the National service framework for coronary heart disease will lead to an improvement in the care of these vulnerable patients.

The structure of EMMACE Study Group (evaluation of methods and management of acute coronary events) is as follows: principal investigators-Alistair S Hall, Michael B Robinson clinical coordinator - Robert J Sapsford; research assistants-Beryl M Jackson, Christine Morrell; statistical advisor-Darren C Greenwood; database management-J Oldham; key investigators-RJI Bain, SG Ball, PD Batin, KE Berkin, RM Boyle, JL Caplin, RS Clark, JC Cowan, J Dhawan, D Garg, G Kaye, S Khan, H Larkin, RV Lewis, AF Mackintosh, J McLenachan, MA Memon, LCA Morley, GW Morrison, MS Norrell, EJ Perrins, MM Pye, G Reynolds, NP Silverton, JH Smyllie, U Somasundram, RN Stevenson, JB Stoker, AP Tandon, LB Tan, CIP Welsh, C Weston, GJ Williams, PT Wilmshurst, JI Wilson, AV Zezulka.

This project was commissioned and funded by the NHS Research and Development Programme. RJS thanks Merck Sharp \& Dohme for partial financial support and K Woods and Sharp \& Dohme for partial financial support and K Woods and
J Cowley for early advice. We wish to thank all the staff in the J Cowley for early advice. We wish to thank all the staff in the
biochemistry departments, coronary care units, audit and codbiochemistry departments, coronary care units, audit and codand all non-cardiology consultants of the 20 acute hospitals in the former Yorkshire Region as well as M Allen at the Office for National Statistics. We want to thank Mr Phil Warburton for his help with the graphic for this report.

1 Kannel WB, Abbott RD. Incidence and prognosis of unrecognised myocardial infarction. An update on the Framingognised myocardial infarction. An update on
ham study. N Engl f Med 1984;311:1144-7.

2 Uretsky BF, Farquhar DS, Berezin AF, et al. Symptomatic myocardial infarction without chest pain: prevalence and clinical course. Am f Cardiol 1977;40:498-503.

3 Goldstein RE, Boccuzzi SJ, Cruess D. Prognosis after hospitalisation for acute myocardial infarction not accompanied by typical ischemic chest pain. The multicenter diltiazem postinfarction trial research group. Am $\mathcal{F}$ Med 1995;99: 123-31

4 Muller RT, Gould LA, Betzu R, et al. Painless myocardial infarction in the elderly. Am Heart f 1990;119:202-4.

5 Herlitz J, Karlson BW, Richter A, et al. Prognosis for patients with initially suspected acute myocardial infarction in rela-

6 Milner KA, Funk M, Richards S, et al. Gender differences in symptom presentation associated with coronary heart disease. Am f Cardiol 1999;84:396-9.

7 Bayer AJ, Chada JS, Farag RR, et al. Changing presentation of myocardial infarction with increasing old age. $\mathcal{F} \mathrm{Am}$ Geriatr Soc 1986;34:263-6. 
8 Gunnar RM, Passamani ER, Bourdillon PD, et al. Guidelines for the early management of patients with acute myocardial infarction. A report of the American College of Cardiology/American Heart Association task force on assessment of diagnostic and therapeutic cardiovascular procedures. I Am Coll Cardiol 1990;16:249-92.

9 The Acute Infarction Ramipril Efficacy (AIRE) Study Investigators. Effect of ramipril on mortality and morbidity of survivors of acute myocardial infarction with clinical evidence of heart failure. Lancet 1993;342:821-8.

10 Pfeffer MA, Braunwald E, Moye LA, et al. Effect of captopril on mortality and morbidity in patients with left ventricular dysfunction after myocardial infarction. Results of the survival and ventricular enlargement trial. The SAVE investigators. N Engl f Med 1992;327:669-77.
11 The 4S Study. Randomised trial of cholesterol lowering in 4444 patients with coronary heart disease: the Scandinavian simvastatin survival study (4S). Lancet 1994;344: 1383-9

12 Chan WK, Leung KF, Lee YF, et al. Undiagnosed acute myocardial infarction in the accident and emergency department: reasons and implications. Eur $\mathcal{F}$ Emerg Med 1998;5:219-24.

13 Dorsch MF, Lawrance RA, Sapsford RJ, et al. A simple benchmark for evaluating quality of care of patients following acute myocardial infarction Heart (in press).

14 Meyer BJ, Meier B, Bonzel T, et al. Interventional cardiology in Europe 1993. Working group on coronary circulation of the European Society of Cardiology. Eur Heart f 1996;17: 1318-28.

\section{IMAGES IN CARDIOLOGY}

\section{Aortico-atrial fistula secondary to bacterial endocarditis}

A 39 year old woman was admitted to hospital for investigation and management of a febrile illness of six weeks' duration. She was haemodynamically stable but a grade $4 / 6$ continuous murmur, best heard at the left sternal edge, was noted. A diagnosis of bacterial endocarditis was made after blood cultures grew viridans streptococci. Treatment with intravenous penicillin and gentamicin was begun.

A communication between the right aortic sinus of Valsalva and the right atrium (RA) was seen on transoesophageal colour Doppler echocardiography (right, arrow). No vegetations were identified. A significant left to right shunt (Qp:Qs 2:1) was evident at cardiac catheterisation. Left ventriculography confirmed the presence of an aortico-atrial communication, with contrast filling the right heart. At surgery a $15 \mathrm{~mm}$ defect in the right aortic sinus was noted, communicating with the right atrium and associated with vegetations. There was no aneurysmal dilatation of the sinuses of Valsalva. The defect was closed with a Goretex patch, but in order to obliterate the communication effectively, it was necessary to replace the aortic valve with a prosthetic valve. The patient made an uneventful recovery.

Rupture of an aortic sinus of Valsalva aneurysm into an adjacent cardiac chamber is a well

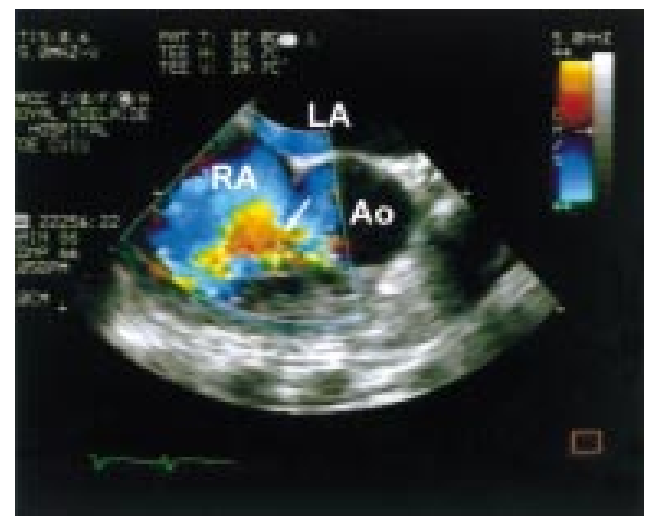

recognised, albeit uncommon, condition. In contrast, rupture of an aortic sinus in the context of bacterial endocarditis without a preexisting aneurysm is a rare occurrence. In the clinical setting of bacterial endocarditis and no valvar vegetations on echocardiography, a high index of suspicion is required to allow early diagnosis of this condition and referral for cardiac surgery as indicated.

H M OMAR FAROUQUE STEPHEN G WORTHLEY RICHARD A S YEEND omar.farouque@med.monash.edu.au 